\title{
GEOSPATIAL CLUSTERING OF GASTROSCHISIS IN POLAND: DATA FROM THE POLISH REGISTRY OF CONGENITAL MALFORMATIONS (PRCM)
}

\section{ANNA MATERNA-KIRYLUK , BARBARA WIĘCKOWSKA ${ }^{2}$, KATARZYNA WIŚNIEWSKA ${ }^{3}$, MAŁGORZATA CZYŻEWSKA ${ }^{4}$,} URSZULA GODULA-STUGLIK ${ }^{5}$, MAŁGORZATA BAUMERT ${ }^{6}$, RYSZARD MARGOL ${ }^{7}$, and ANNA LATOS-BIELEŃSKA ${ }^{1}$

${ }^{1}$ Poznan University of Medical Sciences, Poznań, Poland

Department of Medical Genetics

${ }^{2}$ Poznan University of Medical Sciences, Poznań, Poland

Department of Computer Science and Statistics

${ }^{3}$ Poznan University of Medical Sciences, Poznań, Poland

Department of Preventive Medicine

${ }^{4}$ Wroclaw Medical University, Wrocław, Poland

Department and Clinic of Neonatology

${ }^{5}$ Medical University of Silesia, Katowice, Poland

Department of Pediatrics in Zabrze

${ }^{6}$ Medical University of Silesia, Katowice, Poland

Department of Neonatology

${ }^{7}$ Poviat Hospital, Nysa, Poland

Neonatal Unit

\begin{abstract}
Objectives: The aims of this study were: to evaluate the prevalence of abdominal wall defects in the Polish population, to analyze temporal trends in the prevalence, to identify areas (clusters) of high risk of abdominal wall defects, and to characterize, with respect to epidemiology, children with abdominal wall defects and their mothers in the area defined as a cluster. Material and Methods: We used isolated congenital malformations (gastroschisis Q79.3 and omphalocele Q79.2 according to the International Statistical Classification of Diseases and Related Health Problems, 10th revision (ICD-10, the extended version)) data reported to the Polish Registry of Congenital Malformations (PRCM) over the years 19982008 based on the population of 2362502 live births. We analyzed 11 administrative regions of Poland with complete epidemiologic data. Results: Of 11 regions, 2 had a significantly higher standardized prevalence of isolated gastroschisis: Dolnośląskie (1.7/10 000 live births, $p=0.0052)$ and Śląskie $(1.9 / 10000$ live births, $p<0.0001)$. Furthermore, within the region of Dolnośląskie, we defined a clear prevalence of the isolated gastroschisis cluster $(\mathrm{p}=0.023)$. We comprehensively examined demographic and socio-economic risk factors for abdominal wall defects in this area, and we found that these factors failed to account for the cluster. Conclusions: We identified a distinct prevalence cluster for isolated gastroschisis, although a precise reason for the disease clustering in this region remains unknown. Cluster identification enables more focused research aimed at identification of specific factors with teratogenic effects.
\end{abstract}

Key words:

Gastroschisis, Omphalocele, Congenital malformations, Scan statistic, Spatial and temporal clusters, Epidemiology

The project: "Polish Registry of Congenital Malformations" was supported by Centre for Health Care Information Systems (contract No.: CSIOZ/147/2014). Project manager: Prof. Anna Latos-Bieleńska.

Received: March 2, 2015. Accepted: June 24, 2015.

Corresponding author: A. Materna-Kiryluk, Poznan University of Medical Sciences, Department of Medicial Genetics, Rokietnicka 8, 60-806 Poznań, Poland (e-mail: akiryluk@ump.edu.pl); B. Więckowska, Poznan University of Medical Sciences, Department of Computer Science and Statistics, Dąbrowskiego 79, 60-529 Poznań, Poland (e-mail: basia@ump.edu.pl). 


\section{INTRODUCTION}

An increase in the prevalence of gastroschisis has been reported in the last 50 years. A significant increase of gastroschisis was noted at the beginning of 1970s in Scandinavian countries, and later in other various European countries, Australia, Japan and USA [1-3].

Based on the data from 21 registers included in the European Registry of Congenital Anomalies and Twins (EUROCAT), the prevalence of gastroschisis (Q79.3 according to the International Statistical Classification of Diseases and Related Health Problems, 10th revision (ICD-10, the extended version) [4]) constituted 0.94 per 10000 births between 1980 and 1990 [5], but it was twice as high 2.35 per 10000 births in the years 1998-2008 [6].

One of the better established risk factors is young maternal age $(<20$ years old), but the exact mechanism underlying this association is not well understood [5,7-9]. The following risk factors have been previously suggested: primiparity [10], low socio-economic status, the use of tobacco and alcohol [11-13], drug use [12,14] and oral contraceptive use in the 1st trimester of pregnancy [15]. The recent increase in the prevalence of gastroschisis affects infants of mothers across all ages, thus, an independent exogenous factors are likely to play a role [16].

Identification of isolated gastroschisis clusters allows a study of etiology of gastroschisis; it also enables more focused research aimed at identification of specific teratogenic factors in the affected high risk regions [17-19]. Interventions aiming at the control of factors may become critical in the primary prevention of congenital malformations such as gastroschisis.

The aims of this work were to evaluate the prevalence of abdominal wall defects in the Polish population, to analyze temporal trends in the prevalence, to identify areas (clusters) of high risk of abdominal wall defects, and to characterize, with respect to epidemiology, children with abdominal wall defects and their mothers in the area defined as a cluster.

\section{MATERIAL AND METHODS}

The analysis took into account live births registered in the Polish Registry of Congenital Malformations (PRCM) from birth to 2 years of age, in which isolated gastroschisis (Q79.3) and omphalocele (Q79.2) were recognized. Organizational structure of the PRCM and the methods of collecting and storing information concerning congenital malformations have been previously reported in detail [20]. The captured data include: date of birth, gravidity, birth weight, gestational age at delivery, sex, age at diagnosis, parental age at birth, parental education, parental occupation, parental consanguinity, pregnancy risk factors (including maternal diseases, medications, addictions), prenatal diagnosis, family history including previous pregnancies, information whether the child was born alive, karyotype and autopsy examination results if available.

Evaluation was conducted over the years 1998-2008 in a population comprising 2362502 live births in the area of 11 Polish voivodeships (of 16 covered by the PRCM), which amounted to $57.3 \%$ of all live births in the Polish population in those years. The analysis comprised 11 Polish voivodeships: from 1998 - Dolnośląskie, Kujawsko-Pomorskie, Lubuskie, Opolskie, Pomorskie, Wielkopolskie, WarmińskoMazurskie and Zachodniopomorskie, from 2001 - Śląskie, and from 2002 - Lubelskie and Podkarpackie.

The PRCM reporting system is voluntary, and information about congenital malformations is reported using paper forms and electronic entries from the following sources: pediatric units, maternity wards, departments of surgery, child health clinics, specialized medical clinics, general practitioners and genetics clinics. In addition to the passive sources of information mentioned above, an active system of collecting information was implemented in Wielkopolskie voivodeship (1998-2008). Within the framework of the active reporting system, clinical records of all newborns in the whole voivodeship were monitored by trained employees from the PRCM aiming to comprehensively capture all suspected cases of congenital malformations. 
Encoding malformations was based on the International Statistical Classification of Diseases and Related Health Problems, 10th revision (ICD-10, the extended version) [4] and it was conducted according to the EUROCAT guidelines prepared by the Committee on Classification and Coding of Malformations [21]. Two experienced clinical geneticists encoded the malformations. Information concerning the number of births in the years 1998-2008 in the analyzed region came from the Regional Data Bank of the Central Statistical Office [22].

Only a diagnosis of gastroschisis (Q79.3) or an omphalocele (Q79.2) without any other major, accompanying malformations was qualified as an "isolated disorder." Coefficient of prevalence of a given congenital malformation was calculated as a ratio of the number of children with the malformation to the general number of live births in the years 1998-2008. Standardized ratios were calculated by the use of data about live births in Poland in the years 1998-2008 in 6 age categories of a mother's age: $\leq 19$ years, 20-24 years, 25-29 years, 30-34 years, $35-39$ years, and $\geq 40$.

A cluster of congenital malformations was defined as such an aggregation of cases of congenital malformations, in time and/or space, which seems to be unusual. Administrative districs (the administrative subregions of maternal residence) were used as units in the geospatial analysis. Because of the lack of published data about births in particular categories of maternal age in the years 1998-2001 with a breakdown into administrative districs, the analysis of clusters was conducted based on the standardized coefficients according to the maternal age in the years 2002-2008.

To evaluate the effects of time in each region, a test of a linear time trend of the standardized prevalence coefficients for isolated gastroschisis (Q79.3) and isolated omphalocele (Q79.2) was performed for each voivodeship. Moreover, the standardized coefficients of prevalence in 10 voivodeships (passive reporting) were compared with the prevalence of Wielkopolskie voivodeship (active reporting system). This conservative approach allowed identification of voivodeships with the highest prevalence of isolated gastroschisis (Q79.3) or omphalocele (Q79.2), despite the inherent problem of under-reporting in passive data collection methods. Taking into account the breakdown of the indicated voivodeships into administrative districs, an analysis was conducted in order to identify clusters (areas with the increased prevalence of the defects) of isolated abdominal wall defects. Spatial, temporal and spatial-temporal clusters were evaluated.

Once clusters were localized, demographic characteristics of mothers and their children born with an isolated abdominal wall defect and residing within a given cluster were compared with analogous characteristics for Wielkopolskie voivodeship. The following characteristics were analyzed: an infant's sex, gestational age, birth weight, parental ages, parental education, the gravidity, previous spontaneous abortions, family history with the same condition and substance abuse during pregnancy, including tobacco use.

\section{Statistics}

The following methods were used in the comparative analyses: for comparison of categorical variables we used the $\mathrm{Chi}^{2}$ test, or the Fisher's exact test (small sample sizes); for continuous variables we used the Student's t-test or the Student's t-test with Cochran-Cox correction, and the Mann-Whitney test (non-normally distributed data). The linear trend was tested by the use of the Pearson's correlation. Clusters were searched for by the use of the Kulldorff's scan statistic [23]. Statistical significance of a cluster was tested with the likelihood ratio test, the distribution and p-value of which were estimated by the use of the Monte-Carlo method. For all statistical tests, the type I error rate $(\alpha)$ of 0.05 was deemed statistically significant. Statistical calculations, charts and maps were prepared by the use of the PQStat version 1.4.8 software. The SatScan version 9.2 software was used to search for clusters. 


\section{RESULTS}

The crude prevalence of isolated gastroschisis (Q79.3) in Wielkopolskie voivodeship (the reference region) was 1.2 per 10000 live births, and 1.1 per 10000 live births after standardization based on maternal age. In the same years, of the analyzed voivodeships, 2 had a significantly higher standardized prevalence of isolated gastroschisis (Q79.3), i.e., Dolnośląskie (1.7/10 000, p = 0.0052) and Śląskie $(1.9 / 10000, \mathrm{p}<0.0001)$ voivodeships (Table 1). The prevalence of isolated omphalocele (Q79.2) was, on average, lower than the prevalence of isolated gastroschisis (Q79.3). We observed no regional differences in the prevalence of isolated omphalocele (Q79.2). Moreover, we detected no significant temporal trends in the prevalence of isolated gastroschisis (Q79.3) or omphalocele (Q79.2), standardized according to a mother's age, neither in Wielkopolskie voivodeship nor in any of the remaining voivodeships (Table 2).

Next, we analyzed geospatial clusters of the increased prevalence of isolated gastroschisis (Q79.3) in the years 20022008 in order to identify high risk subregions within Dolnośląskie and Śląskie voivodeships (Figure 1, Table 3). In Dolnośląskie voivodeship, a spatial cluster of isolated gastroschisis (Q79.3) (an area with an increased prevalence of the defect) comprising 68 administrative districs reached statistical significance with $p=0.023$ by the Kulldorff's scan statistic. In Śląskie voivodeship a cluster of isolated gastroschisis (Q79.3) comprising 13 administrative districs was identified, but it did not reach statistical significance $(\mathrm{p}=0.066)$.

Finally, we compared demographic and socio-economic characteristics of the cases reported within the clusters to those reported in Wielkopolskie voivodeship (Table 4). We detected no significant differences in the demographic and socio-economic risk factors between these regions suggesting that other, yet unexplained, factors may underlie the observed patterns. We also analyzed details of maternal occupation in the Dolnośląskie

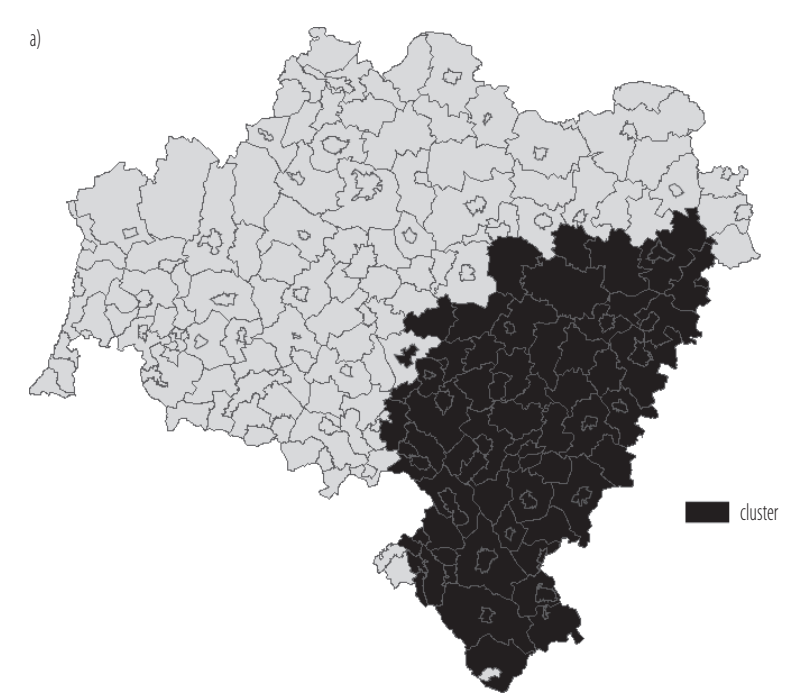

b)

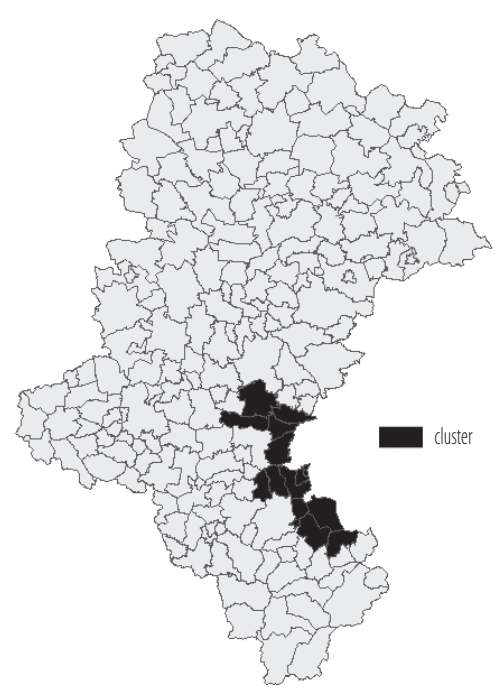

Fig. 1. Clusters - areas with the increased prevalence of isolated gastroschisis in a) Dolnośląskie and b) Śląskie voivodeships

voivodeship cluster, but detected no predominance of a specific profession (among the mothers giving birth to affected children, there were 4 students, 4 retail employees, 3 unemployed, 2 teachers, and others with a range of professions including a hair dresser, waiter, technician, tailor, renovator, architect, cook, etc.). The data on dietary supplementation during pregnancy was incomplete and could not be analyzed. Notably, none of the mothers suffered from chronic illness, such as diabetes or hypertension. 


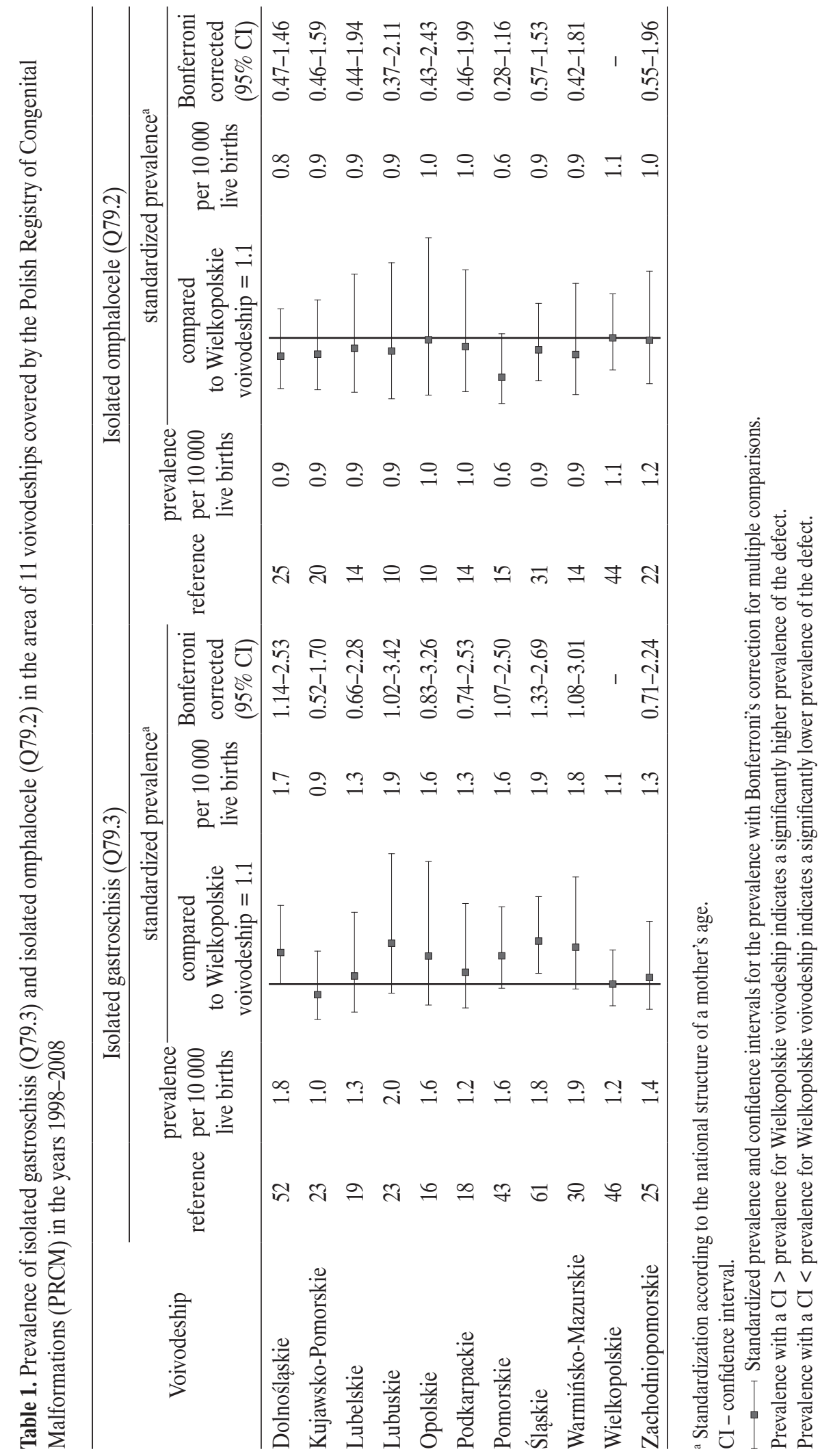


Table 2. Statistical significance of the linear trends of the standardized prevalence for isolated gastroschisis (Q79.3) and isolated omphalocele (Q79.2) in the area of 11 voivodeships covered by the Polish Registry of Congenital Malformations (PRCM) in the years 1998-2008

\begin{tabular}{|c|c|c|c|c|}
\hline \multirow{3}{*}{ Voivodeship } & \multicolumn{4}{|c|}{ Pearson's linear correlation } \\
\hline & \multicolumn{2}{|c|}{ isolated gastroschisis (Q79.3) } & \multicolumn{2}{|c|}{ isolated omphalocele (Q79.2) } \\
\hline & $\mathrm{p}$ & correlation coefficient & $\mathrm{p}$ & correlation coefficient \\
\hline Dolnośląskie & 0.8402 & 0.07 & 0.9762 & 0.01 \\
\hline Kujawsko-Pomorskie & 0.2667 & 0.37 & 0.3038 & 0.30 \\
\hline Lubelskie & 0.3718 & 0.40 & 0.7471 & 0.75 \\
\hline Lubuskie & 0.1518 & 0.46 & 0.5052 & 0.51 \\
\hline Opolskie & 0.1481 & 0.47 & 0.9138 & 0.91 \\
\hline Podkarpackie & 0.2416 & 0.51 & 0.4127 & 0.41 \\
\hline Pomorskie & 0.6052 & 0.18 & 0.6687 & 0.67 \\
\hline Śląskie & 0.5181 & 0.27 & 0.8195 & 0.82 \\
\hline Warmińsko-Mazurskie & 0.9603 & 0.02 & 0.6680 & 0.67 \\
\hline Wielkopolskie & 0.1573 & 0.46 & 0.6903 & 0.69 \\
\hline Zachodniopomorskie & 0.0872 & -0.51 & 0.7304 & 0.73 \\
\hline
\end{tabular}

Table 3. Kulldorff's scan statistic for space, space-time and space clusters of isolated gastroschisis (Q79.3) in the years 2002-2008

\begin{tabular}{lcc}
\hline \multirow{2}{*}{ Most likely cluster } & \multicolumn{2}{c}{ Kulldorff's scan statistic } \\
\cline { 2 - 3 } & Dolnośląskie voivodeship & Śląskie voivodeship \\
\cline { 2 - 3 } Space & 0.0230 & 0.0660 \\
Space-time & 0.2890 & 0.3180 \\
Time & 0.5300 & 0.1690 \\
\hline
\end{tabular}

Table 4. Demographic and socio-economic characteristics of the cases with isolated gastroschisis (Q79.3) in the cluster of Dolnośląskie voivodeship compared to Wielkopolskie voivodeship (reference) in the years 1998-2008

\begin{tabular}{|c|c|c|c|}
\hline Characteristic & $\begin{array}{c}\text { Cluster of } \\
\text { Dolnośląskie } \\
\text { voivodeship } \\
(\mathrm{N}=23)^{\mathrm{a}}\end{array}$ & $\begin{array}{l}\text { Wielkopolskie } \\
\text { voivodeship } \\
\quad(\mathrm{N}=32)^{\mathrm{a}}\end{array}$ & $\mathrm{p}^{\mathrm{b}}$ \\
\hline Place of residence $[\mathrm{n}]$ & & & 0.48 \\
\hline urban & 13 & 15 & \\
\hline rural & 10 & 17 & \\
\hline $\operatorname{Sex}[n]$ & & & 0.10 \\
\hline female & 8 & 19 & \\
\hline male & 14 & 13 & \\
\hline
\end{tabular}


Table 4. Demographic and socio-economic characteristics of the cases with isolated gastroschisis (Q79.3) in the cluster of Dolnośląskie voivodeship compared to Wielkopolskie voivodeship (reference) in the years 1998-2008 - cont.

\begin{tabular}{|c|c|c|c|}
\hline Characteristic & $\begin{array}{c}\text { Cluster of } \\
\text { Dolnośląskie } \\
\text { voivodeship } \\
(\mathrm{N}=23)^{\mathrm{a}}\end{array}$ & $\begin{array}{l}\text { Wielkopolskie } \\
\text { voivodeship } \\
\quad(\mathrm{N}=32)^{\mathrm{a}}\end{array}$ & $\mathrm{p}^{\mathrm{b}}$ \\
\hline Gestation [n] & & & 1.00 \\
\hline singelton & 23 & 31 & \\
\hline multiple & 0 & 0 & \\
\hline Gestational age [week] $(\mathrm{M} \pm \mathrm{SD})$ & $36.8 \pm 2.2$ & $36.7 \pm 1.6$ & 0.88 \\
\hline Birth weight $[g](M \pm S D)$ & $2530.0 \pm 428.1$ & $2564.3 \pm 507.1$ & 0.80 \\
\hline Gravidity $[\mathrm{n}(\%)]$ & & & 0.84 \\
\hline 1 & $16(69.6)$ & $23(71.9)$ & \\
\hline 2 & $4(17.4)$ & $6(18.8)$ & \\
\hline$\geq 3$ & $2(8.7)$ & $2(6.3)$ & \\
\hline Previous spontaneous abortions [n $(\%)]$ & $3(13.0)$ & $1(3.1)$ & 0.27 \\
\hline Substance abuse during pregnancy $[\mathrm{n}(\%)]$ & $2(8.7)$ & $0(0.0)$ & 0.51 \\
\hline Smoking $[\mathrm{n}(\%)]$ & $2(8.7)$ & $0(0.0)$ & 0.51 \\
\hline Mother's education $[\mathrm{n}(\%)]$ & & & 0.51 \\
\hline primary education & $4(17.4)$ & $3(9.4)$ & \\
\hline basic vocational education & $5(21.7)$ & $2(6.3)$ & \\
\hline undergraduate education & $10(43.5)$ & $7(21.9)$ & \\
\hline higher education & $2(8.7)$ & $3(9.4)$ & \\
\hline Father's education [n (\%)] & & & 0.42 \\
\hline primary education & $1(4.3)$ & $0(0.0)$ & \\
\hline basic vocational education & $7(30.4)$ & $4(12.5)$ & \\
\hline undergraduate education & $7(30.4)$ & $6(18.8)$ & \\
\hline higher education & $3(13.0)$ & $3(9.4)$ & \\
\hline Family history with the same condition [n (\%)] & $0(0.0)$ & $0(0.0)$ & 1.00 \\
\hline
\end{tabular}

M - mean; SD - standard deviation.

${ }^{a}$ Marginal totals for some variables may be different because of missing values.

${ }^{\mathrm{b}}$ All values statistically insignificant.

Statistical significance for pairwise comparisons between the groups of cases was evaluated with the Student's t-test (or Cochran-Cox correction where appropriate) for continuous variables; the Mann-Whitney U test for ordered categorical variables; the Chi ${ }^{2}$ test for unordered categorical variables.

\section{DISCUSSION}

Our study identified an area of high risk of isolated gastroschisis (Q79.3) in the region of Dolnośląskie. Our results are based on a large population-based registry that surveyed over $57 \%$ of live births in Poland over the years 1998-2008. Considering that large population registers of congenital malformations based on the passive data collection methods may underestimate the prevalence due to under-reporting [24], we instituted an active system of data collection to complement the passive sources of information in one of the studied regions Wielkopolskie voivodeship. Accordingly, the prevalence 
data from this voivodeship was used as a reference for comparison of other regions.

To further reduce heterogeneity of the studied defects, we excluded those children in whom the malformations occurred as a consequence of chromosomal abnormalities, or in the setting of recognized syndromes or multiple malformations. Proper classification of abdominal wall defects is often challenging [25]. Although the diagnoses of abdominal wall defects were made by qualified neonatologists and verified by 2 clinical geneticists, we recognized that in some cases false positive reports might have occurred (e.g., classifying a ruptured omphalocele as gastroschisis). However, despite those limitations our study detects a significant cluster of isolated gastroschisis in Dolnośląskie voivodeship.

In many highly developed countries a mother's young age $(<20)$ was a risk factor of gastroschisis [5,7,8]. This association may reflect a number of lifestyle and behavioral factors that increase the risk of malformations during pregnancy. Our previous study has confirmed that not only maternal age, but also young paternal age constituted an independent risk factor of the occurrence of isolated gastroschisis [9]. Considering the known effects of parental age, our analyses required standardization according to a mother's age, and thus, our conclusions should be robust to this potential confounder.

Although our data on the prevalence of gastroschisis in the area of 10 voivodeships may have been incomplete, in 9 out of 10 voivodeships, the standardized prevalence coefficients were higher compared to Wielkopolskie voivodeship. Most significantly higher standardized prevalence coefficients were found in Dolnośląskie voivodeship (1.7 per 10000 births) and Śląskie voivodeship (1.9 per 10000 births). Considering that the passive registration system may miss some cases, we can conservatively assume that the real prevalence of gastroschisis in those areas is even higher than the reported one.
Using the Kulldorff's scan statistic, we identified a statistically significant spatial cluster of isolated gastroschisis (Q79.3) in Dolnośląskie voivodeship - it comprised 68 administrative sub-regions $(p=0.023)$. Notably, in 1999 a spatio-temporal cluster of the increased prevalence of isolated cleft lip and palate was identified in the same area [26]. Clusters of gastroschisis and isolated cleft lip and palate overlapped by $67.6 \%$ (46 administrative districts).

As we mentioned before, several exogenous factors increasing the risk of a birth of a child with gastroschisis have been studied previously. Therefore, we performed a comprehensive comparison of demographic characteristics of the children born with gastroschisis (Q79.3) and of their mothers within the cluster with those who were born in the reference region of Wielkopolskie voivodeship. We detected no significant differences in these factors.

These findings may suggest the effect of yet unidentified factors in the area of the detected cluster. Further research will be needed to define the exact nature of the harmful exposure, but several important facts about these regions need to be discussed. Most notably, both Dolnośląskie and Śląskie regions have the highest levels of urbanization and industrialization in Poland. In Dolnośląskie voivodeship, urban and industrial areas comprise $71 \%$ of the total voivodeship area, and in Śląskie voivodeship this percentage is even higher $-79 \%$. In contrast, the urban/industrial area of Wielkopolskie voivodeship constitutes $57 \%$ of the region, and for other voivodeships that number ranges $41-69 \%$ [22]. Some of the prior studies have suggested urban areas as high risk areas for gastroschisis, for example, including Finland [27], the United States [28], and northern areas of Great Britain [29,30]. Moreover, these 2 regions rank as the top polluters, with some of the highest shares of industrial waste generated in Poland and estimated at $27.6 \%$ for Dolnośląskie and $33.3 \%$ for Śląskie voivodeship. For comparison, the percentage waste for the remaining voivodeships ranges $0.7-5.5 \%$ [31]. 


\section{CONCLUSIONS}

Our cluster analysis clearly narrows the high risk area to 68 administrative districs of Dolnośląskie voivodeship, facilitating further studies aimed at identification of specific teratogenic factors within the cluster.

\section{REFERENCES}

1. Bugge M, Holm NV. Abdominal wall defects in Denmark, 1970-89. Paediatr Perinat Epidemiol. 2002;16:73-81, http://dx.doi.org/10.1046/j.1365-3016.2002.00392.x.

2. Castilla EE, Mastroiacovo P, Orioli IM. Gastroschisis: International epidemiology and public health perspectives. Am J Med Genet C Semin Med Genet. 2008;148C:162-79, http://dx.doi.org/10.1002/ajmg.c.30181.

3. Kirby RS, Marshall J, Tanner JP, Salemi JL, Feldkamp ML, Marengo L, et al. Prevalence and correlates of gastroschisis in 15 states, 1995 to 2005. Obstet Gynecol. 2013;122(2 Pt 1): 275-81, http://dx.doi.org/10.1097/AOG.0b013e31829cbbb4.

4. International Statistical Classification of Diseases and Related Health Problems. 10th revision. World Health Organization; 2010.

5. Calzolari E, Bianchi F, Dolk H, Milan M. Omphalocele and gastroschisis in Europe: A survey of 3 million births 1980-1990. EUROCAT Working Group. Am J Med Genet. 1995;58:187-94, http://dx.doi.org/10.1002/ ajmg.1320580218.

6. EUROCAT [Internet]. Prevalence tables. EUROCAT; 2013 [cited 2013 Jun 17]. Available from: http://www.eurocat-network.eu/accessprevalencedata/prevalencetables.

7. Byron-Scott R, Haan E, Chan A, Bower C, Scott H, Clark K. A population-based study of abdominal wall defects in South Australia and Western Australia. Paediatr Perinat Epidemiol. 1998;12:136-51, http://dx.doi.org/10.1046/j.13653016.1998.00090.x.

8. Loane M, Dolk H, Bradbury I. Increasing prevalence of gastroschisis in Europe 1980-2002: A phenomenon restricted to younger mothers? Paediatr Perinat Epidemiol. 2007;21: 363-9, http://dx.doi.org/10.1111/j.1365-3016.2007.00820.x.
9. Materna-Kiryluk A, Wiśniewska K, Badura-Stronka M, Mejnartowicz J, Więckowska B, Balcar-Boroń A, et al. Parental age as a risk factor for isolated congenital malformations in a Polish population. Paediatr Perinat Epidemiol. 2009; 23:29-40,http://dx.doi.org/10.1111/j.1365-3016.2008.00979.x.

10. Rittler M, Castilla EE, Chambers C, Lopez-Camelo JS. Risk for gastroschisis in primigravidity, length of sexual cohabitation, and change in paternity. Birth Defects Res A Clin Mol Teratol. 2007;79:483-7, http://dx.doi.org/10.1002/bdra.20364.

11. Hackshaw A, Rodeck C, Boniface S. Maternal smoking in pregnancy and birth defects: A systematic review based on 173687 malformed cases and 11.7 million controls. Hum Reprod Update. 2011;17:589-604, http://dx.doi.org/10.1093/ humupd/dmr022.

12. Mac Bird T, Robbins JM, Druschel C, Cleves MA, Yang S, Hobbs CA. Demographic and environmental risk factors for gastroschisis and omphalocele in the National Birth Defects Prevention Study. J Pediatr Surg. 2009;44:1546-51, http:// dx.doi.org/10.1016/j.jpedsurg.2008.10.109.

13. Stoll C, Alembik Y, Dott B, Roth MP. Risk factors in congenital abdominal wall defects (omphalocele and gastroschisi): A study in a series of 265858 consecutive births. Ann Genet. 2001;44:201-8, http://dx.doi.org/10.1016/S00033995(01)01094-2.

14. Werler MM, Sheehan JE, Mitchell AA. Maternal medication use and risks of gastroschisis and small intestinal atresia. Am J Epidemiol. 2002;155:26-31, http://dx.doi.org/ 10.1093/aje/155.1.26.

15. Waller DK, Gallaway MS, Taylor LG, Ramadhani TA, Canfield MA, Scheuerle A, et al. Use of oral contraceptives in pregnancy and major structural birth defects in offspring. Epidemiology. 2010;21:232-9， http://dx.doi.org/10.1097/ EDE.0b013e3181c9fbb3.

16. Suita S, Okamatsu T, Yamamoto T, Handa N, Nirasawa Y, Watanabe Y, et al. Changing profile of abdominal wall defects in Japan: Results of a national survey. J Pediatr Surg. 2000;35:66-72, http://dx.doi.org/10.1016/S0022-3468 (00)80016-0. 
17. Root ED, Meyer RE, Emch ME. Evidence of localized clustering of gastroschisis births in North Carolina, 1999-2004. Soc Sci Med. 2009;68(8):1361-7, http://dx.doi.org/10.1016/ j.socscimed.2009.01.034.

18. Elliott L, Loomis D, Lottritz L, Slotnick RN, Oki E, Todd R. Case-control study of a gastroschisis cluster in Nevada. Arch Pediatr Adolesc Med. 2009;163(11):1000-6, http://dx.doi. org/10.1001/archpediatrics.2009.186.

19. Yazdy MM, Werler MM, Anderka M, Langlois PH, Vieira VM. Spatial analysis of gastroschisis in Massachusetts and Texas. Ann Epidemiol. 2015;25(1):7-14, http://dx.doi.org/ 10.1016/j.annepidem.2014.10.001.

20. Latos-Bieleńska A, Materna-Kiryluk A; PRCM Working Group. Polish Registry of Congenital Malformations - Aims and organization of the registry monitoring 300000 births a year. J Appl Genet. 2005;46:341-8.

21. Khoshnood B, Greenlees R, Loane M, Dolk H; EUROCAT Project Management Committee; EUROCAT Working Group. Paper 2: EUROCAT public health indicators for congenital anomalies in Europe. Birth Defects Res A Clin Mol Teratol. 2011;91 Suppl 1:S16-22, http://dx.doi. org/10.1002/bdra.20776.

22. Central Statistical Office of Poland [Internet]. Warszawa: The Office; 1995-2015. Local data bank, 2013 [cited 2013 Jun 17]. Available from: http://www.stat.gov.pl/bdr/.

23. Kulldorff M. A spatial scan statistic. Commun Stat Theory Methods. 1997;26:1481-96, http://dx.doi.org/10.1080/ 03610929708831995.

24. Lie RT. Environmental epidemiology at the Medical Birth Registry of Norway; strengths and limitations. Cent Eur J Public Health. 1997;5:57-9.
25. Torfs C, Curry C, Roeper P. Gastroschisis. J Pediatr. 1990; 116:1-6, http://dx.doi.org/10.1016/S0022-3476(05)81637-3.

26. Materna-Kiryluk A, Więckowska B, Wiśniewska K, Czyżewska M, Godula-Stuglik U, Jaworska-Bobkier R, et al. Spatial and temporal clustering of isolated cleft lip with or without cleft palate in Poland. Int J Environ Health Res. 2014;24(6):567-79, http://dx.doi.org/10.1080/09603123. 2014.883593.

27. Hemminki K, Saloniemi I, Kyyronen P, Kekomaki M. Gastroschisis and omphalocele in Finland in the 1970s: Prevalence at birth and its correlates. J Epidemiol Community Health. 1982;36:289-93, http://dx.doi.org/10.1136/ jech.36.4.289.

28. Roeper PJ, Harris J, Lee G, Neutra R. Secular rates and correlates for gastroschisis in California (1968-1977). Teratology. 1987;35:203-10, http://dx.doi.org/10.1002/tera.1420350206.

29. Tan KH, Kilby MD, Whittle MJ, Beattie BR, Booth IW, Botting BJ. Congenital anterior abdominal wall defects in England and Wales 1987-1993: Retrospective analysis of OPCS data. BMJ.1996;313(7062):903-6, http://dx.doi.org/ 10.1136/bmj.313.7062.903.

30. Stone DH, Rimaz S, Gilmour WH. Prevalence of congenital anterior abdominal wall defects in the United Kingdom: Comparison of regional registers. BMJ. 1998;317(7166): 1118-9, http://dx.doi.org/10.1136/bmj.317.7166.1118.

31. Voivodship Inspectorates for Environmental Protection. [Report on the state of the environment in the Lower Silesia Region in 2007] [Internet]. Wrocław: The Inspectorates; 2013 [cited 2013 Jun 17]. Available from: http://www. wroclaw.pios.gov.pl/index.php/publikacje/raporty-o-staniesrodowiska/. Polish.

This work is available in Open Access model and licensed under a Creative Commons Attribution-NonCommercial 3.0 Poland License - http://creativecommons.org/ licenses/by-nc/3.0/pl/deed.en. 